\title{
GLOBAL PROBLEMS AND GLOBAL RESPONSIBILITIES OF SCIENCE
}

\author{
Sudarat Srima \\ Suan Sunandha Rajabhat University, Bangkok, Thailand
}

According to many political analysts fear has become an integral part of the present day political processes. The dynamics of nowadays development and the flow of negative information which pervades society require that scientists, devoted to their studies, spend adequate time for making their scientific results popular, for fighting against pseudo-science, for explaining the regional and global problems which our society faces today. The presentday era is totally different from the previous stages of humankind history. The main characteristic features of the present day are at least four: the dynamic development of science and technologies, the existence of weapons of mass destruction, the horrifying environmental pollution and growth in population. All these characteristic features of the present have a global character. In the time of globalization people should unite because they have a common destiny on Earth - the co-existence or non-existence. Global problems require global responsibilities. It is scientists who should be among the first to form new horizons for humankind

Keywords: fear, catastrophic events, global warming, modern threats facing humanity, flights to other planets.

\section{Introduction}

For billions of years before humans appeared on this planet the evolution of living organisms has managed to solve all emerging contradictions through self-organization only. In many cases life suffered massive losses but new ways for evolutionary progress were always found. This has changed with the emergence of "rational human beings".

Our major problem is that human never managed to become a truly integral element of the natural biochemical cycles on this planet. In other words, humans are still an external factor in relation to biosphere. For us as human, this can be a philosophical or existential problem. This quote from the Bulgarian writer Pavel Vezhinov might seem too poetic first but it is essential much more serious and scientific than one might think: “... the nightingales were pouring out their souls in songs as ever. They had no problems, like Nature, prior to the creation of man".

Let's back to current reality though. Today's most serious global hazards include:

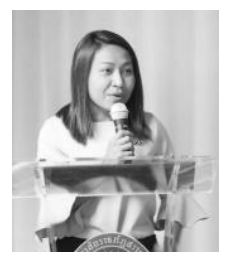

Sudarat Srima

Lecturer in Suan Sunandha Rajabhat University, Bangkok, Thailand

Research interests: education, innovative leaning, teaching methodology

Published more than 15 papers in international journals, participated in 9 International conferences.

e-mail: sudarat.sr@ssru.ac.th 


\section{GLOBAL PROBLEMS AND GLOBAL RESPONSIBILITIES}

- drastic growth of the world population (1 billion in 1800, 7 billion in 2011 and as many as $8+$ billion are expected in 2030);

- urbanization and rapid growth of megapolises;

- aggressive exploitation of all detected natural resources;

- massive deforestation; expansion of the desert on the areas that used to be very much naturally productive;

- destruction of unique habitats that can't be recreated artificially;

- decreasing biodiversity;

- large-scale pollution of air, soils and waters;

- rapidly decreasing volumes of drinking water;

- genetic modifications in organisms that eventually might cause losses of unique genetic identities of local species;

- accumulation of greenhouse gas effects and the accompanying climate changes, together known as global warming.

At first glance, the problem of population seems to be no threat at all: current population of the world $(7+b l n)$ can settle in the area of Texas, provided (!) it has the population density of the New York City. But it is not about population numbers alone, the key problem is about resources - food, water and energy in the first place (Palumbi, 2001).

Ongoing today rapid urbanization is one of the most serious environmental threats since half of the Earth's population is already residing in cities. The currently happening enlargement of megapolises worldwide is quite alarming from the standpoint of both researchers and policy-makers (Clark et al., 2001; Huntington, 1996). As of today, there are already 20+ megapolises with the population over $10 \mathrm{mln}$ people, an both these numbers will be only increasing in the near future. There is also another stable trend observed: urbanization actively redirects population to countries' coastline, while global warming is gradually rising the sea levels, thus making living on the coastline probably not the best idea for all.

\section{Exploitation of natural resources}

Evolution would have been impossible without natural resources. And it is quite obvious by now that mineral resources, such as oil, gas, coal, various ores, non-metalliferous minerals and precious metals are the most important ones. At the same time, all these resources are essentially non-renewable, some of them being more quickly exhaustible, others - not so quickly. As of today there is hardly any place on this planet which is not subject (current or potential) of exploitation of mineral resources, the only exception being Antarctica, though many countries have already voiced their intention to cover it as well in the near future already.

Another acute problem with natural resources is constant shortage of drinking water in so many countries and regions worldwide. The Earth is so frequently called "the blue planet" because of its vast water, however, $97.5 \%$ of these waters are saline, while the bulk of fresh water is stored in glaciers. Moreover, the volumes of fresh water are quickly decreasing. Some experts explain this by climate changes, others are of the opinion that this is due to constantly increasing use of fresh water by various industrial activities (Kennedy, 1994; Nicolis et al., 1977). A research by American Goldman Sachs demonstrates that world 
consumption of drinking water doubles every 20 years. This means that in the future its price will be higher than that of oil and gold.

Some people hold the opinion that desalinating ocean water is a good solution to this problem. However, desalinating waters from seas and oceans needs tremendous amounts of energy, and this makes this solution a truly vicious circle. Thus, the only realistic conclusion seems to be quite predictable: there is a need for developing a new global policy aimed at more economical use of drinking water across the whole planet.

Future economy growth must be also based on smarter use of natural resources. Back in 1972 already the Club of Rome produced a study titled "The Limits to Growth". Its core idea is that there is no system that can grow endlessly. Therefore, well balanced development is needed for keeping the equilibrium in natural systems. Lack of balance in the development may have truly catastrophic results.

Another vitally serious problem concerns massive deforestation, expansion of desert areas. Together these two processes lead to destruction of habitats and losses in biodiversity. According to the UN data, over 12,5 mln ha of forests are cleared off every year. Most endangered of them are tropical forests which are home to $80 \%$ of all biological species on this planet. The environmental balance is also damaged by newer industrial methods applied in agriculture overall and stock-breeding in particular.

Truly enormous forest areas are being cleared to free more lands for agricultural activities. Moreover, cultivation of some grain crops (rice, for example) assumes flooding of vast areas, and this has its negative influence on the environment overall. Other forests are being destroyed due to exploitation of mineral resources, this concerns tropical and subtropical areas in the first place. All this damages the natural cycle of carbon dioxide and methane exchange. Today's forest areas are already unable to regulate the current amount of $\mathrm{CO} 2$ in the atmosphere, thus causing its increase. In parallel to that, huge territories under rice with all their swamping are releasing significant amounts of methane. At the same time, $\mathrm{CO} 2$ emissions vary depending on both industry volumes and deforestation. Ruddiman (2005) analyzed in great deal of detail the historical data and revealed that the bulk of forest areas in both Europe and Asia were destroyed much earlier than the industrial era actually started.

Thus, what can we learn from our own history? Contemporary mankind is not the first civilization to face a climate-related crisis. Many societies in the long history of the humankind had environmental problems but only a few of them managed to change their style of living to avoid complete decline and destruction.

Besides, mankind overall has been always threatened by various natural disasters -earthquakes and volcanoes, floods, forest fires and so on.

We are used to think of Homo sapiens as the major product and the peak of biological evolution, not comparable to other species on the Earth. However, human activities as well as non-activities are actually causing deaths for a long list animals and plants. Some even go as far as stating that the whole biological life on this planet may get back to the bacterial stage in development "thanks to" us, humans. The Earth, most probably, will continue to exist in any case, as a planet it many exist several billion years more; however, under such scenario it will stay nearly fully lifeless. If we really have enough common sense, we should not allow this scenario happen. However, developing a better perspective would surely require totally different and brand new knowledge as well as sufficient common sense to control all the 


\section{GLOBAL PROBLEMS AND GLOBAL RESPONSIBILITIES}

achievements of intelligence. And what we need to keep in mind at all times: the Nature and all its resources are limited.

\section{Climate Changes and Their Consequences}

Today we can observe quite many dangers, some of them being natural, others are man-made, but this does not necessarily mean that we are not at the end of the world.

Global warming is often considered to be the cornerstone of all these threats. Everyone who dares to oppose to the idea of global warming will be heavily criticized (Clark et al., 2001). Still, there are people who state that global warming is actually part of global climate fluctuations in the Earth's history, and there is nothing extraordinary about it.

The climate system of this planet has been formed and is still under the permanent influence of several following factors (Broecker, 1975): (1) variations in Sun radiation, caused by processes on the Sun itself; (2) changes in the orbital parameters of the Earth predetermined by its movement around the Sun; (3) geological (tectonic) processes which change the Earth's internal structure, the movement of its lithosphere plates, mountain systems, oceans and other features of the planet's geomorphology. These factors can be also regrouped differently: as external factors (astronomical) and internal ones (geophysical, geological and geographical). Besides, there is no such notion as "average or normal" climate of the Earth. Climate on this planet has always demonstrated cyclic oscillations, there were warmer and colder episodes of different duration.

According to Noam Mohr (a physicist at Yale University, USA), a major share of greenhouse gases (including, first of all, methane) are caused by livestock at farms. In other words, if all of us opt for a vegetarian diet (fully or at least partially), meat consumption and production will go down, thus, this major source of methane will be reduced significantly.

Such and similar view are not that popular. Though it is getting more and more attraction, among younger generations of humans especially: the best way to hinder global warming is to cut or completely eliminate the consumption of products with animal origin.

At the same time, global warming indeed has a hidden threat inside it, mostly because it is causing drastic climate changes, and the latter turn into natural disasters which take thousands of live and live millions of people without a shelter.

On the other side, in terms of energy production and consumption, global warming seems to be much more profitable as compared to global cooling. For example, warmer temperatures during the winter time means less energy consumed on heating. At the same time, global warming lead to higher ocean levels, and this might have devastating consequences for many islands, primarily those in the Pacific and Indian oceans. Same might be applicable to many large cities located on the continental coastlines. Minor global warming which took place in the late 20th century has been caused by astronomic factors but not by human activity, although after that, the role of people (via industrial activity and fossil fuels use in the first place) rose dramatically.

Today revising the global pattern in the direction to more sustainable development on the grounds of changing civilizational principles and new philosophy becomes an obvious necessity. This also means that a new system of values is urgently needed, the one that would be able to bring humankind in harmony with the new natural conditions. This, ideally, includes new education for everyone - from kids at school to high-rank politicians. Ignorance 
in the form of the illusion that people may have the absolute power over the Nature is a highly dangerous thing.

Global warming is a fact, no matter what caused it and/or what might it its explanations, it is, in any case, the result of cyclic processes related to orbital factors. A minor increase of the average annual temperature on the Earth is observed worldwide, and this fact is also undisputable. This trend is additionally enhanced by the intensified pollution of the environment and atmosphere, both being caused by various human activities. If negative effects from human beings are not restricted really soon, we could state with confidence that in the near future already the mankind will suffer catastrophic consequences, including thousands of human victims and enormous losses of material assets. This would not be the end of the world, most probably, but it could leave a deep trace in the geological history of this planet, comparable to the extinction of dinosaurs, for example.

We are living in a highly dynamic environment which has very short time intervals for changes, sometimes, only a decade is needed for a truly radical change to take place. This rate of change can be favourable for us sometimes but it does not promise stable prosperity though. Moreover, people themselves represent one of the most disturbing factors in this regard. All further development of our civilization is the decisive factor for acceleration of global climate changes on the Earth. Adaptation to ongoing climate changes is vitally necessary for the whole mankind with the view of more balanced (sustainable) development seen as the coevolution of the nature and human society. Most probably, we will not be able to stop climate change, but we can at least try to reduce negative human influences on the environment.

\section{A New Man is Born: Will There be Species Different From Homo Sapiens?}

This is one of the evolution laws: changing world can be studied only by the humans that are "constructed differently", as their integrated intellect combines hereditary features from our common ancestors as well as new features formed under the influence of the brand new factors.

Someone once said that people today are all like children (Born, 1968). They want to know the truth, but they must not be constantly threatened by it. As it is well noted by Karl Popper, the mankind should create such a society which would have freedom but at the same time it also should have enough security. We already have no illusions concerning "paradise on Earth", however, there is a reasonable alternative to that -- peaceful competition without any pathological symptoms as it used to be in the previous century.

We all need to remember one simple thing: there is only one planet to live on. Therefore, our common future strongly depends on unity and peace. Life on this planet can be destroyed not only due to nuclear war or other global ecological catastrophe; it can be easily destroyed due to banal ignorance and indifference.

For billions of years before us, the evolution has somehow found an optimal decision, no matter what were the obstacles. Today we can only hope that this logic of evolution will not be broken due to presence of the so-called Homo sapiens.

It is already very much obvious that in the near future the humankind will have to overcome a range of difficulties, however, we have some reasons to be optimistic. Moreover, since the major problems experienced today by the Earth have been caused by human activity, they must be resolved by the Man since the latter clearly has the controlling. 


\section{GLOBAL PROBLEMS AND GLOBAL RESPONSIBILITIES}

There is no doubt we got lucky with a planet which has been providing all of us with the most favorable conditions for life and development. Our evolution differentiated us from all other mammals, the Homo sapiens species gradually started to outstand, and today we call ourselves "the reasonable man". Ironically, this name does not seem to be fully justified as of today, considering everything what's happening on our planet. Some of these events are actually natural, other are more like unreasonable activities by the so-called sapiens.

In other words, the actual threats for the Earth are coming not from natural geological processes and phenomena, but rather from human impacts. Our planet today is already looking like an overloaded Noah's Ark. Can it survive the flood which might be caused by global warming? That depends on the common sense of the man and in particular - on whether this common sense would be allowed to control the achievements of intelligence.

And we can only be hopeful that the man will justify - by actual deeds - its current name of the "creature of reason" - the Homo Sapiens.

\section{References:}

Born, M. (1968). My life and my views. Charles Scribner's sons. New York.

Broecker, W. S., (1975). Climatic change: are we on the brink of a pronounced global warming? Science, 189. 460-463.

Chomsky, N. (1967). The Responsibility of Intellectuals. The New York Review of Books, 23, 1967.

Clark J.S., Carpenter S.R., Barber M. et al. (2001). Ecological forecast: An emerging imperative. Science, 293, 657-660.

Crichton, M. (2004). State of fear. Harper Collins, New York.

Huntington, S. P. (1996). The Clash of Civilizations and the Remaking of World Order. Simon \& Schuster, New York.

Kennedy, P. (1994). Preparing for the Twenty-First Century. Random House, Inc., New York. Nicolis, G. and Prigogine, I. (1977). Self-organization in nonequilibrium systems: From IJOI. Retrieved: http://www.ijoi-online.org/

Palumbi S.R. (2001). Humans as the world greatest evolutionary force. Science, 293, 1786-1790.

Ruddiman, W.F. (2005). How did humans first alter global climate? Scientific American, 3, 34-41.

Paper submitted

Paper accepted for publishing

Paper published online
02 April 2019

26 May 2019

25 June 2019 